\title{
Percepción de los profesionales de enfermeira sobre la integración del acompañante durante el proceso de parto
}

\section{Perception of professional nursing on the companion of inclusion in the process of parturition}

\section{Percepção dos profissionais de enfermagem sobre a inserção do acompanhante no processo de parturição}

\footnotetext{
Alexandra do Nascimento Cassiano ${ }^{1}$, Milena Gabriela dos Santos Silva ${ }^{2}$, Flávio Lopes Alves ${ }^{3}$, Amandda Thaise de Sousa Barbosa ${ }^{4}$, Flávia Andréia Pereira Soares dos Santos ${ }^{5}$, Bertha Cruz Enders ${ }^{6}$, Nilba Lima de Souza

${ }^{1}$ Mestranda em Enfermagem pela Universidade Federal do Rio Grande do Norte. Rua Monsenhor Emerson Negreiros, Santa Cruz, Rio Grande do Norte, Brasil.E-mail: anc_enfa@hotmail.com. Telefone: (84) 999502265.

${ }^{2}$ Especialista em Saúde Materno Infantil pela Universidade Federal do Rio Grande do Norte.

${ }^{3}$ Especialista em Enfermagem Obstétrica pela Universidade Federal do Rio Grande do Norte.

${ }^{4}$ Especialista em Enfermagem Obstétrica pela Faculdade de Tecnologia de Curitiba.

${ }^{5}$ Mestre em enfermagem pela Universidade Federal do Rio Grande do Norte.

${ }^{6,7}$ Doutora em Enfermagem pela Universidade Federal do Rio Grande do Norte.
}

Cómo citar este artículo en edición digital: Cassiano, A.N., Santos, M.G., Alves, F.L., Barbosa, A.T.S., Santos, F.A.P.S., Enders, B.C. \& Souza, N.L. (2017). Percepción de los profesionales de enfermeira sobre la integración del acompañante durante el proceso de parto. Cultura de los Cuidados (Edición digital), 21(48).

Recuperado de< http://dx.doi.org/10.14198/cuid.2017.48.17>

\section{Correspondência:}

Universidade Federal do Rio Grande do Norte. Rua Monsenhor Emerson Negreiros, Santa Cruz, Rio Grande do Norte. Correo electrónico: anc_enfa@hotmail.com.

Recibido: 19/12/2016; Aceptado: 07/03/2017

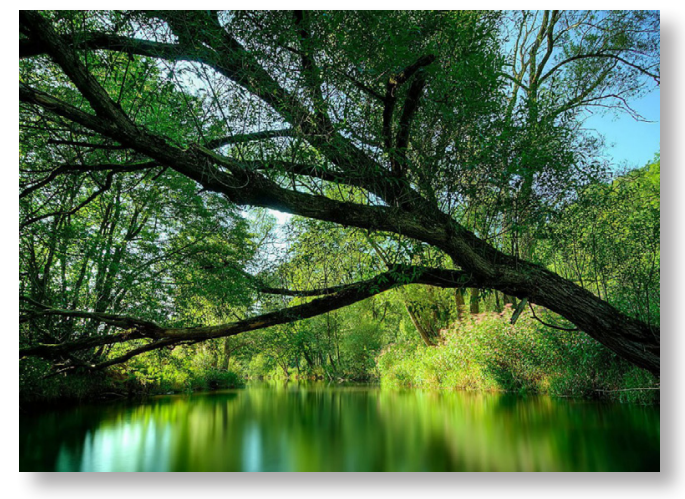

ABSTRACT

The research aimed to identify the nursing knowledge about the insertion of companion in the parturition process. exploratory and descriptive study with qualitative approach developed in a university hospital in the city of Santa Cruz, Rio Grande do Norte, Brazil. The number of participants was determined by saturation data, respecting the inclusion and exclusion criteria. Data were collected through a semi-structured interview, later worked according to content analysis according to Bardin and analyzed according to the principles of symbolic interactionism of Blumer. The escort was valued for its importance, which runs through the emotional support, joint participation and rights guaranteed by law. However, factors linked to the lack of knowledge, inexperience and curiosity were found to be factors that may compromise the care routine. Nursing professionals recognize the importance of accompanying, which moves through the emotional support, guid- 
ance and co-participation in right guaranteed by law.

Keywords: Women's health, midwifery, obstetric nursing, medical companions.

\section{RESUMEN}

Objetivo: La investigación tuvo como objetivo identificar los conocimientos de enfermería sobre la integración del acompañante en el proceso del parto. Método: Estudio exploratorio y descriptivo con enfoque cualitativo desarrollado en un hospital universitario de la ciudad de Santa Cruz, Rio Grande do Norte, Brasil. El número de participantes fue determinado por los datos de saturación, respetando los criterios de inclusión y exclusión. Los datos fueron recolectados a través de una entrevista semiestructurada, más tarde trabajó de acuerdo con el análisis de contenido según Bardin y analizados de acuerdo con los principios de la interacción simbólica de Blumer. Resultados: El acompañamiento se valora debido a su importancia, que se extiende a través del apoyo emocional, la participación conjunta y los derechos garantizados por la ley. Sin embargo, se encontró que los factores vinculados a la falta de conocimiento, falta de experiencia y la curiosidad constituyen factores que puedan comprometer la rutina de cuidado. Conclusiones: Los profesionales de enfermería reconocen la importancia de acompañamiento, que se desarrolla a través del apoyo emocional, orientación y de su participación en derecho garantizado por la ley.

Palabras clave: Salud de la mujer, obstetricia, enfermería obstétrica, acompañamiento.

\section{RESUMO}

A pesquisa teve o objetivo de identificar o conhecimento da enfermagem sobre a inserção do acompanhante no processo de parturição. Estudo exploratório e descritivo, com abordagem qualitativa desenvolvido em um hospital universitário no município de Santa Cruz, Rio Grande do Norte, Brasil. O número de participantes foi determinado por saturação de dados, respeitando aos critérios de inclusão e exclusão. Os dados foram coletados por meio de uma entrevista semiestruturada, ulteriormente trabalhados de acordo com a análise de conteúdo segundo Bardin e analisados conforme os princípios do Interacionismo Simbólico de Blummer. O acompanhante foi valorizado por sua importância, a qual perpassa pelo apoio emocional, coparticipação e direito garantido por lei. Entretanto, fatores atrelados à falta de conhecimento, inexperiência e curiosidade foram referenciados como fatores que podem comprometer a rotina assistencial. Os profissionais de enfermagem reconhecem a importância do acompanhante, a qual perpassa pelo apoio emocional, coparticipação sob orientação e direito garantido por lei.

Descritores: Saúde da mulher, obstetrícia, enfermagem obstétrica, ccompanhantes de pacientes.

\section{INTRODUÇÃO}

Nos primórdios da assistência obstétrica as mulheres pariam em seus lares, acompanhadas por familiares e parteiras, os quais lhes proporcionavam suporte físico e emocional. No entanto, as altas taxas de morbimortalidade maternas e perinatais, na época, resultaram em mudança no panorama vigente. Durante o século XX, o parto foi institucionalizado e passou a ocorrer em ambiente hospitalar, com prioridade ao aspecto tecnológico em detrimento a subjetividade feminina (Alves, Bruggeman, Bampi, Godinho, 2013).

Contudo, as inovações tecnológicas e terapêuticas não conseguiram abranger o real 
sentido deste evento, o qual deveria enfatizar o protagonismo da mulher, bem como, valorizar suas necessidades e direitos. Neste sentido, a partir da década de 80 , um movimento pela reordenação da assistência obstétrica se disseminou mundialmente, proveniente dos esforços da medicina baseada em evidências e do ativismo feminino (Diniz, D’Orsi, Domingues, Torres, Dias, Schneck, Lansky, Teixeira, Rance, Sandall, 2014; Lacerda, Silva, Silva, 2014).

Com esta perspectiva, em 1984, o Ministério da Saúde criou o Programa de Assistência Integral à Saúde da Mulher (PAISM), baseado na prestação de serviços qualificados de assistência ao pré-natal, parto, puerpério imediato e atendimento clínico-ginecológico. Além disso, em 1996 a Organização Mundial de Saúde (OMS) propõe as boas práticas de atenção ao parto e nascimento no intuito de orientar os trabalhadores da saúde quanto a ações comprovadamente eficazes no partejamento (Brasil, 1984; Bruggeman, Oliveira, Martins, Alves, Gayeski, 2013).

No ano 2000, por meio da Portaria no 569, é lançado o Programa pela Humanização do Pré-natal e Nascimento (PHPN) para expandir, consolidar e qualificar o atendimento a gestante, a puérpera e ao recém-nascido. Posteriormente, publicou-se a Lei 11.108/2005, também conhecida como a "Lei do acompanhante", que assegura nos serviços da rede própria ou conveniada ao Sistema Único de Saúde (SUS) a presença de um ente querido, de escolha da parturiente, durante todo o processo de parturição (Brasil, 2005; Andreucci, Cecatti, 2011).

No Nordeste, os resultados preliminares do projeto Nascer no Brasil revelam que 71\% das mulheres foram acompanhadas durante este período. No Rio Grande do Norte, diversos estabelecimentos assistenciais de saúde, como o
Hospital Universitário Ana Bezerra (HUAB) e a Maternidade Escola Januário Cicco (MEJC) preconizam de fato o estabelecido por lei. Ressalta-se que a inserção do acompanhante no HUAB antecede a publicação desta legislação, sendo praticada desde 1998 (Costa, 2007; Silva, Silva, Santos, Rego, 2014).

Em 2011, como estratégia para consolidação da assistência humanizada a mulher e a criança, o Ministério da Saúde (MS) lança através da Portaria 1459, a Rede Cegonha, a qual enaltece ações de atenção à saúde, como o ingresso de um acompanhante, apontado pela mulher, desde o acolhimento até o puerpério imediato (Brasil, 2011). Neste contexto, mediante os avanços nas políticas públicas direcionadas à obstetrícia, o enfermeiro adentra este cenário na medida em que é caracterizado como agente ativo na promoção da Política de Humanização Hospitalar ao Parto (PHPN) e, grande incentivador na inserção de acompanhantes em centros obstétricos (Costa, 2007).

Assim, o enfermeiro busca contribuir para redução nos índices de mortalidade materna e perinatal, com elevação no registro de partos normais, por dispensarem um cuidado centrado nas necessidades biopsicossociais da mulher e de seu ente querido, de modo que este se sintaco-participativo e empoderado quanto ao nascimento.

Diante do exposto, a escolha pela temática ocorreu a partir da vivência das pesquisadoras em um hospital universitário, destarte, questiona-se: qual a percepção da enfermagem acerca da presença do acompanhante durante o processo de parturição?. A partir dessa problematização, objetivou-se com este estudo: identificar o conhecimento da enfermagem sobre a inserção do acompanhante no processo de parturição. 


\section{MÉTODO}

Estudo exploratório e descritivo com abordagem qualitativa, desenvolvido nos setores de Pré-parto, Parto e Pós-parto (PPP), Alojamento conjunto (AC) e Centro Cirúrgico (CC) do Hospital Universitário Ana Bezerra (HUAB), Rio Grande do Norte, Brasil, junto a nove enfermeiros e seis técnicos de enfermagem, perfazendo um total de 15 profissionais atuantes nos referidos setores.

A seleção dos participantes teve como critério de inclusão os membros da equipe com experiência em obstetrícia maior/igual há um ano e foram excluídos os profissionais que estavam de férias, licença ou afastados por motivo de doença no período destinado a realização da coleta de dados. O número de participantes foi determinado pela saturação dos dados, a qual ocorre quando não se visualiza informações adicionais que contribuam para o desenvolvimento do estudo, sendo este um critério para interrupção da coleta (Flick, 2009).

O projeto teve aprovação do Comitê de Ética e Pesquisa (CEP) da Faculdade de Ciências do Trairi (FACISA), veiculado a Universidade Federal do Rio Grande do Norte (UFRN), CAAE $n^{\circ} 42930215.7 .0000 .5568$, parecer $n^{\circ}$ 1.002.117 e aquiescência dos profissionais mediante assinatura do Termo de Consentimento Livre e Esclarecido (TCLE).

Os dados foram coletados no mês de maio de 2015, por meio de uma entrevista semiestruturada contendo informações que caracterizaram os sujeitos e uma questão norteadora do estudo, para tanto, fez-se uso de um gravador de voz digital e, posteriormente, os depoimentos foram transcritos na íntegra para o programa Microsoft Word versão 2013. Vale ressaltar que para garantir o anonimato dos depoentes, a cada participante foi atribuído um nome fictício de pedra preciosa.
$\mathrm{Na}$ etapa de processamento, análise dos dados e interpretação das informações, os depoimentos foram trabalhados de acordo com a análise de conteúdo segundo Bardin, composta pelas etapas: 1) pré-análise; 2) exploração do material; e, 3) tratamento dos resultados, inferência e interpretação. Além disso, os resultados serão analisados conforme os princípios do Interacionismo Simbólico de Herbet Blummer. Para este sociólogo, as pessoas se comportam com as coisas em função do significado que as mesmas possuem para eles; prontamente refere que esse significado advém da interação social que a pessoa tem com seus semelhantes; por fim, defende que, a depender de um processo interpretativo, os significados podem ser alterados, sofrer manejamento e/ou utilizados pela pessoa para lidar com as coisas que ela se depara nas situações cotidianas (Blummer, 1969).

\section{RESULTADOS E DISCUSSÃO}

Os dados apresentados no Quadrol correspondem a uma breve caracterização dos sujeitos da pesquisa. Os envolvidos no estudo eram profissionais de enfermagem com predominância do sexo feminino que se enquadravam na faixa etária entre 20 e 30 anos. De fato, a supremacia feminina demonstra uma característica típica à identidade profissional da enfermagem ao longo dos anos. Em estudo similar, também com enfoque obstétrico, ressaltou-se a predominância feminina em atividades laborais referentes a prestação desse cuidado (Villela, Galastro, Freitas, Santos, Nottaro, 2011).

O tempo de formação dos profissionais predominante foi superior a 20 anos, embora o tempo de experiência em obstetrícia tenha prevalecido o período entre 1 e 10 anos, observa-se que, quase a metade dos profissionais 
investigados atuavam na área a mais de onze anos s. A trajetória profissional na assistência é fundamental para uma reflexão acerca da temática em estudo.

A releitura dos depoimentos foi realizada com o intuito de categorizar as informações com enfoque na semântica das palavras emitidas. Ulteriormente, foi feita a reavaliação dos registros, construídas as inferências e a interpretação. Do processamento dos dados emergiram duas categorias, a saber: cesso parturitivo, conforme evidenciado nas falas a seguir:

É muito importante, principalmente para a questão da paciente se sentir mais segura com a presença de seu familiar. Ela se sente protegida, por que tem alguém para defende-la, ampará-la e consolá-la neste momento tão temido que é o trabalho de parto. (Jadeíte)

Eu entendo que é de uma importância imensa para a parturiente e para equipe. $\mathrm{O}$ acompanhante presente propicia para gestante

\section{Quadro 1}

Caracterização do sujeito da pesquisa segundo sexo, idade, tempo de formação e tempo de experiência em obstetrícia. Santa Cruz, Rio Grande do Norte, 2015.

\begin{tabular}{|c|c|c|}
\hline \multicolumn{3}{|c|}{ SEXO } \\
\hline & $f$ & $\%$ \\
\hline Feminino & 13 & 86,7 \\
\hline Masculino & 02 & 13,3 \\
\hline \multicolumn{3}{|c|}{ IDADE } \\
\hline & $f$ & $\%$ \\
\hline $20 \dashv 30$ anos & 05 & 33,3 \\
\hline $30-40$ anos & 03 & 20 \\
\hline $40-50$ anos & 04 & 26,7 \\
\hline Acima de 50 anos & 03 & 20 \\
\hline \multicolumn{3}{|c|}{ TEMPO DE FORMAÇAO } \\
\hline & $f$ & $\%$ \\
\hline $1 \dashv 5$ anos & 05 & 33,3 \\
\hline $6-10$ anos & 01 & 6,7 \\
\hline $11 \dashv 20$ anos & 02 & 13,3 \\
\hline Mais de 20 anos & 07 & 46,7 \\
\hline \multicolumn{3}{|c|}{ TEMPO DE EXPERIENCIA EM OBSTETRICIA } \\
\hline & $f$ & $\%$ \\
\hline$>1 \dashv 10$ anos & 08 & 53,4 \\
\hline $11-20$ anos & 03 & 20 \\
\hline $21-30$ anos & 02 & 13,3 \\
\hline $31-40$ anos & 02 & 13,3 \\
\hline
\end{tabular}

Fonte: Dados da pesquisa.

Apresentação das categorias temáticas (Quadro 2).

\section{A importância do acompanhante no proces- so de parturição}

Os profissionais entrevistados reconhecem a relevância de uma companhia durante o pro- uma segurança e confiança na conduta médica, né? [..] ele também dar apoio tranquilizando a parturiente, faz a ligação entre a equipe e a parturiente, pronto. (Garnet Azul)

As palavras dos depoentes, a importância atribuída a este personagem se relaciona 
ao apoio, tranquilidade, confiança, segurança e proteção ofertados, inclusive,referenciado como elo entre a equipe e a mulher. No mesmo contexto, um estudo realizado em uma maternidade pública, no Estado da Bahia, destaca opapel do acompanhante no suporte emocional e social com relevante expressão na transmissão de segurança e conforto (Santos, Carneiro, Carvalho, Paiva, 2012).

Nesta perspectiva, ao considerarmos que cada pessoa tem por base de suas ações os símbolos por ele interpretados e definidos, a "importância" desse ator social simbolicamente se encontra atrelada a um meio de "suporte emocional" consolidado. panhante, ele também passa a ser coparticipante do cuidado à aquela paciente [...] sempre que eu converso com a parturiente explicando todos os procedimentos, explicando todo processo, eu também procuro ter um contato e direto com aquele acompanhante e, para isso, eu explico tudo, inclusive demando a eles atividades para que ele também possa participar, um exemplo clássico é quando a gente coloca a mulher para alguma atividade não farmacológica, como a realização de massagens, deambulação [...]. (Esmeralda)

\section{Quadro 2}

Apresentação das categorias e subcategorias

\begin{tabular}{|l|l|l|}
\hline \multicolumn{2}{|c|}{ TEMATICA CENTRAL } & \multicolumn{2}{|c|}{ CATEGORIAS } \\
\hline "Percepção dos profissionais de & 1.2 .1 A importância do acompanhante no processo de \\
enfermagem sobre a inserção do & parturição. \\
acompanhante no processo de & & \\
\cline { 3 - 3 } & &
\end{tabular}

Fonte: Dados da pesquisa.

É evidente que este necessita ser integrado à equipe multiprofissional, afim de que se qualifique como forte aliado nos planos terapêuticos adotados, desse modo, tornar-se-á corresponsável pela assistência dispensada à gestante. Para tanto, faz-se necessário empoleirá-lo de suas atribuições, no intuito de que mantenha uma postura ativa no processo, como citado nos depoimentos de Esmeralda e Galena:

A partir do momento em que você orienta tanto a mulher quanto o acom-
Quando você puxa ele como corresponsável pelo processo de parturição, ele participa, mesmo que não esteja muito preparado.

Eu tive até a realidade de uma que eu não tinha um técnico na hora do parto e o acompanhante me ajudou, ficou super feliz, então quando você dar uma liberdade com responsabilidade, ele aceita e participa. Ele tem que se sentir útil. (Galena)

Destarte, este indivíduo será ativo e parti- 
cipativo no trabalho de parto, parto e puerpério imediato, quando o mesmo realizar ações, devidamente orientadas, que contribuam para uma vivência mais tranquila e segura do processo parturitivo, tais como: realização de massagens, incentivo a deambulação, ao banho no chuveiro, ofertar palavras de conforto, promover uma escuta ativa, entre outros.

Corroborando com o exposto, um estudo desenvolvido em um hospital público de Fortaleza-Ceará, também com abordagem qualitativa, enfatiza como atividades pertinentes ao acompanhante: a oferta de apoio emocional, a realização de exercícios e o desenvolvimento de técnicas não farmacológicas para amenização das dores (Dodou, Rodrigues, Guerreiros, Guedes, Lago, Mesquita, 2014).

Ressalta-se, portanto, a necessidade de uma equipe multiprofissional direcionada a promover a inserção desse personagem no cenário de parto, haja vista que a maior parte dos serviços de saúde não ofertam informações consistentes, desse modo, o acompanhante segue despreparado e sem referência no que concerne à sua atuação.

Nos relatos de Turmalina e Ouro percebemos que, por vezes, o acompanhante leigo pode interferir ("atrapalhar") na rotina institucional ou mesmo em condutas profissionais, fato que desencadeia expectativas contraproducentes atreladas à sua inserção na cena do nascimento:

Por muitas vezes eles atrapalham por que não conhecem o processo, e isso dificulta muito, quando você não entende, você acha que a mulher vai morrer [...]. (Turmalina)

$\mathrm{O}$ que atrapalha um pouco, às vezes, é a curiosidade também deles, que eles têm curiosidade e ficam no telefone também, né? Irradiando todo o processo que aqui houve a par-

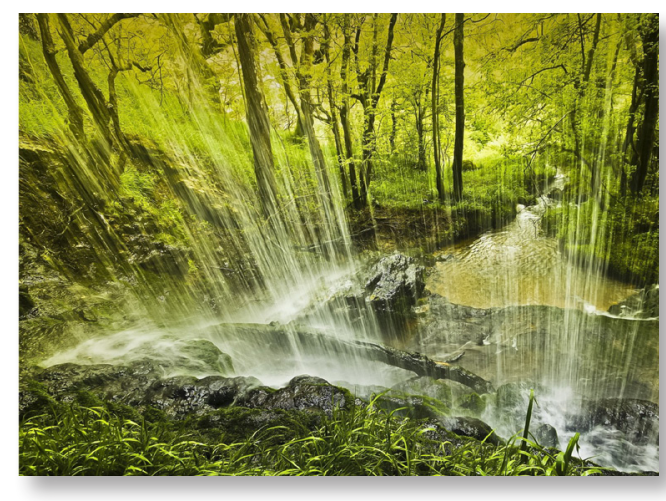

tir do parto até a saída, (risos), então eu acho que esse celular lá dentro atrapalha e, elas querem botar a paciente para falar. (Ouro)

Neste sentido, compreendemos que os entrevistados atribuíram um significado a presença de uma companhia a partir das interações que ocorreram com o mundo de objetos no decorrer de sua vivência laboral, ou seja, situações que geraram algum desconforto, constrangimento ou mesmo, dificultaram a prestação da assistência.

Muitos profissionais acreditam que esse personagem aumenta a demanda de serviço, uma vez que, chegam despreparados e desconhecem o mecanismo de parto. Assim sendo, podem "atrapalhar” a padronização dos cuidados, os quais seguem uma rotina previamente estabelecida em cada instituição de saúde (Bruggemann, Ebsen, Oliveira, Gorayeb, Ebele, 2014).

A inexperiência e o despreparo se relacionam diretamente a fragilidade do sistema em que nos inserimos, neste, os trabalhadores se sentem violados, constrangidos e intimidados com a presença de um indivíduo que venha a interferir em ações e rotinas habituais (Carvalho, Junior, Nunes, Macedo, 2011).

Mesmo diante do panorama atual, a enfermagem reconhece a legitimidade do acompanhante, haja vista ser um direito garantido por lei, a qual integra um direito social e reprodu- 
tivo/sexual com ênfase na equidade e liberdade individual:

Bem, no meu entendimento é antes de mais nada um direito, então por ser uma questão de lei, lei não se questiona, se cumpre (Diamante)

Bom, no meu modo de ver o processo de acompanhante tem uma função primordial, pois é uma forma de transmitir segurança para mesma, né? Pois, a mesma tem o direito garantido por lei de escolher um acompanhante de sua confiança né?. (Topázio)

No Brasil, a lei 11.108 foi sancionada em 07 de abril de 2005 almejando garantir a parturiente o direito a um acompanhante de sua escolha durante todas as etapas do trabalho de parto, parto e pós-parto imediato, dessa maneira, exige-se dos estabelecimentos de saúde um redirecionamento, pois, estamos diante de uma intervenção comportamental que impulsiona opiniões favoráveis e também, contrárias a proposta do governo (Paz, Fensterseifer, 2011).

A categoria em apreço nos revela, dentro de uma perspectiva interacionista, que a "importância" do acompanhante perpassa por concepções de "suporte emocional", "co-participação" e "direito". Visto isso, visualizamos que, apesar de reconhecida a relevância desse personagem, alguns aspectos relativos a inexperiência e conhecimento ainda podem "atrapalhar" o desenvolvimento da assistência a mulher no cenário de nascimento.

\section{Relevância do acompanhante nas consultas de pré-natal}

O pré-natal almeja proporcionar um bom desenvolvimento gestacional, o qual culminará no nascimento de um recém-nascido saudável, abrange, inclusive, fatores psicossociais, culturais e ações educativas (Brasil, 2012). Nesta categoria emerge a percepção dos depoentes em relação a participação do acompanhante nas consultas de pré-natal:

Eu acho que realmente é preciso que seja feito um trabalho no pré-natal[...] para que eles entendam o processo [...]. Eu acho que o pré-natal é a chave de tudo, a partir do pré-natal é possível preparar a mulher e o acompanhante para o parto. (Turmalina)

O profissional elabora um significado para o pré-natal como a "chave de tudo" fundamentado no contexto social de sua prática laboral, onde observa ao interagir com mulheres e acompanhantes devidamente orientados desde as primeiras consultas na Atenção Básica $(\mathrm{AB})$, uma maior facilidade em se inserir no cenário hospitalar, de modo a contribuir com a equipe na prestação de uma assistência qualificada.

Desse modo, identificamos a responsabilidade dos profissionais atuantes na atenção primária em dispensar uma "escuta ativa" a esses usuários, uma vez que, por meio desta, serão esclarecidas as etapas do processo parturitivo, sanadas as dúvidas, elaborado junto a equipe um plano de parto e, por fim, a gestante e sua companhia estarão aptos a participar ativamente das condutas a serem adotadas até o momento do nascimento.

O pré-natal transpõe uma sequência de consultas para acompanhamento clínico ou prevenção de intercorrências, representa a oportunidade para estabelecimento de vínculo, um momento de diálogo com consequente identificação das necessidades socioculturais e emocionais que direcionarão as ações em saúde (moura, Melo, César, Silva, Filha, 2015).

Identificamos que a maioria das entrevistas, no contexto estudado, convergem para in- 
terpretação de que o acompanhante necessita, assim como a gestante, ser "trabalhado", no período pré-natal, enfocando-o como sujeito de direitos e deveres na prestação da assistência. Esta necessidade se torna evidente nas falas de Pérola, Safira e Painite:

A gente acredita que quando o acompanhante é trabalhado no pré-natal junto com essa paciente vemos na nossa experiência que é um acompanhante que ajuda no processo de trabalho de parto $e$ durante o parto. (Pérola)

Os depoimentos acima revelam, sob a ótica do Interacionismo Simbólico, que os profissionais participantes deste estudo estabeleceram um processo interativo com as mais variadas situações vivenciadas em sua rotina de trabalho, levando-as a reputar o pré-natal como instrumento facilitador para integração desse ator social ao momento do parto.

Vale ressaltar que, para ser bem trabalhado junto a gestante, a equipe da $\mathrm{AB}$ deverá incentivar o desenvolvimento das dimensões de apoio à mulher no decorrer da gravidez. Uma dessas dimensões seria o apoio emocional, compreendido como o ato ou efeito do acompanhante incentivar, ouvir e acolher afetivamente; o apoio físico, entendido como o provimento de suporte que minimize as limitações da gravidez, sejam através de massagens, apoio alimentar ou contribuição com as tarefas do lar; o apoio informacional, que envolve a aquisição de conhecimentos necessários a promoção de uma atenção individualizada, abrangendo inclusive, a rotina hospitalar e os direitos garantidos por lei; e, por fim, o apoio de intermediação, com enfoque na companhia como elo entre a mulher e os trabalhadores dos serviços de saúde (Ebsen, 2015).

É evidente que o ente querido só poderá apoiar a gestante de forma holística e priori- zando cada uma das dimensões de apoio supracitadas, se houver um profissional capacitado a lhe ofertar suporte, instrumentalizando-o na promoção do cuidado. O enfermeiro, por se caracterizar como o principal expoente na realização de consultas no pré-natal, é visto por Rubi como norteador neste processo:

Poderia no pré-natal, a enfermeira que faz o acompanhamento com a gestante orientar o acompanhante e não só a mãe, são coisas que ajudariam a equipe de enfermagem e melhoraria para paciente em si (Rubi).

A atenção concedida ao indivíduo que servirá de apoiador durante todo o mecanismo de parturição dependerá da aplicação de práticas comprovadamente eficazes e estabelecimento de vínculos fundamentados em princípios éticos. A garantia de autonomia, privacidade e as trocas com a gestante e seu familiar são essenciais para adoção de condutas futuras (Carvalho, Kerber, 2014).

Muito embora a Lei 11.108/2005 não contemple a presença de um acompanhante nas consultas de pré-natal, o que não acarreta obrigatoriedade às Estratégias de Saúde da Família em aceita-lo, já tramita no Congresso Nacional o projeto de Lei 5656/2013, o qual amplia a presença desse personagem a esse tipo de atendimento. Ademais, a Política Nacional de Atenção Integral à Saúde do Homem (PNAISH), criada em 2008, pelo MS, visualiza a presença do pai como meio de fortalecer o direito masculino em participar de todo o período reprodutivo, desde o acompanhamento da mulher na gestação até o pós-parto (Ebsen, 2015).

Apesar dos esforços em garantir, por meio de políticas públicas, a inserção ativa do acompanhante em consultas de pré-natal, este personagem ainda chega às unidades de 
assistência a mulher com pouca ou nenhuma informação acerca de como proceder durante o nascimento. Para Rubi, existe a necessidade do envolvimento de outros profissionais nas ações educativas ao acompanhante. Para ela os Assistentes Sociais deveriam, portanto, iniciar uma ação educativa e de orientação, a fim de apresentar a rotina hospitalar e elaborar critérios que avaliem a pertinência desse indivíduo no cenário do parto:

Eu acredito que todo acompanhante deveria passar pelo serviço social para ser orientado. Olhe! O trabalho de parto pode ser demorado principalmente quando é primigesta. Ter uma série de critérios para avaliarmos se essa pessoa pode ou não acompanhar a paciente. (Rubi)

Eu acho que a pessoa deveria ser orientada para saber as rotinas do hospital, saber o que se pode fazer num pós-parto para que as coisas acontecesse sem problemas. (Musgravite)

Pelo que consta na Lei do Acompanhante, a parturiente possui o direito de, uma vez adentrando qualquer maternidade no âmbito do Sistema Único de Saúde (SUS), estar amparada por uma pessoa de sua escolha, seja ele o marido, genitora ou outro indivíduo de seu convívio social, durante todo o período de trabalho de parto, parto e pós-parto imediato (Brasil, 2005). Portanto, ao considerarmos esta legislação, não se caracteriza como atribuição de nenhum profissional fomentar a criação de parâmetros que avaliem a pertinência de uma pessoa, selecionada pela cliente, para protagonizar junto a mesma o momento do nascimento.

No entanto, é preciso concordar que o indivíduo que assumirá a função de companhia, em quaisquer condições, deverá ser empoderado acerca do seu papel dentro dos estabeleci-

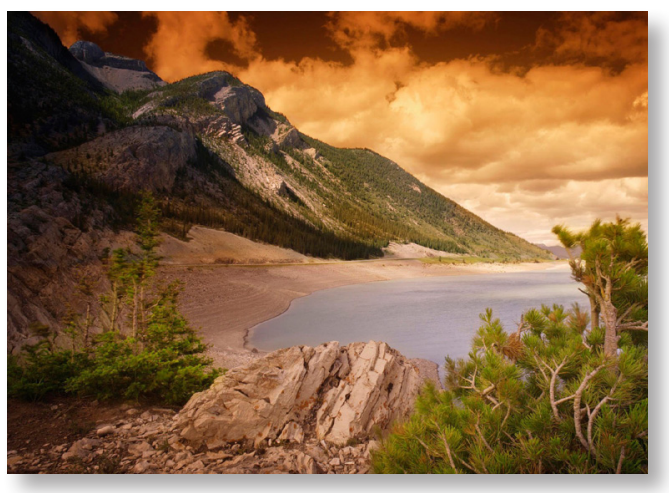

mentos assistenciais, para que assim, o mesmo não seja um mero telespectador perdido nesse processo. Na fala de Cristal, percebe-se uma preocupação em relação à adequação hospitalar para que seja esclarecida a função desse personagem:

Eu acredito que o acompanhante é importante sim durante esse processo, mas que ainda os hospitais precisam se adequar, conseguir esclarecer sobre a importância, o papel desse acompanhante, por que as vezes eu acho que ele fica meio perdido, ele não sabe o tão ou quanto é importante a presença dele alí [...] então eu acho que falta aí um pouco de esclarecimento a este pessoal que chega para ser acompanhante (Cristal).

Decerto, questionamentos podem emergir durante todo o período gravídico-puerperal e, não somente no pré-natal, haja vista cada etapa suscitar novas demandas. Cabe a equipe multiprofissional atuante em hospitais, realizar um bom acolhimento, reforçar o significado positivo desse indivíduo, transpondo os aspectos negativos e enaltecendo a integralidade da atenção ao parto.

Com base no exposto, a categoria em apreço nos revela que os entrevistados reconhecem a relevância do acompanhante em atividades desenvolvidas nas consultas de pré-natal, uma vez que, dentro da perspectiva de humaniza- 
ção ao nascimento, este ator social tem se destacado, inclusive, como norteador de práticas assistenciais e no fortalecimento de evidências científicas.

Entretanto, percebemos também, a necessidade de uma legislação consolidada que assegure sua presença no pré-natal, bem como de um plano de acolhimento hospitalar, que garanta, de fato, sua presença junto a gestante, como fornecedor de apoio emocional, físico, informacional e de intermediação.

\section{CONCLUSÃO}

Ao analisarmos a percepção dos profissionais de enfermagem sobre a inserção do acompanhante, pudemos compreender, na perspectiva do interacionismo simbólico, que este personagem foi valorizado pela sua importância, a qual perpassa pelo apoio emocional ofertado, co-participação sob orientação e direito garantido por lei. Entretanto, fatores atrelados a falta de conhecimento, inexperiência e curiosidade foram referenciados como aspectos que podem comprometer a rotina assistencial, bem como a padronização dos cuidados.

Percebeu-se que, embora alguns entrevistados tenham feito referência à presença do acompanhante como direito social e reprodutivo, outros defendem sua participação mediante preparação em consultas de pré-natal junto a gestante, com ênfase no desenvolvimento das dimensões de apoio, a saber, o apoio emocional, físico, informacional e de intermediação. Embora os estudos mostrem os benefícios desse personagem no pré-natal, comumente estes adentram as maternidades com limitado conhecimento acerca de como proceder no processo de parturição, fato que leva os profissionais a defenderem a construção de parâmetros que avaliem a pertinência desse ator social no cenário de parto, indo de encontro ao preconizado pela Lei 11.108/2005.

No tocante aos sentimentos inerentes a sua permanência na atenção ao nascimento, destacamos o papel positivo, o qual se ancora no suporte biopsicossocial, com ênfase na transmissão de segurança, força e tranquilidade. Como sentimentos negativos, os profissionais ressaltam a inexperiência, o despreparo e a persistência de crenças/mitos/tabus, os quais desencadeiam receio de que a assistência seja partilhada, descentralizando o foco da assistência.

Os resultados desta pesquisa demonstram a primordialidade em se realizar novas discussões sobre enredo estudado, as quais deverão apresentar abordagens metodológicas diferenciadas e, que avaliem também, a percepção da mulher em relação a presença de um acompanhante neste processo, bem como, a qualidade da atenção ofertada à parturiente e sua companhia no hospital campo de pesquisa, para que então, o fenômeno em questão seja melhor caracterizado.

\section{REFERÊNCIAS}

- Alves, M. C., Brüggemann, O.M., Bampi, R. R., \& Godinho, V. G. (2013). Apoio a parturiente por acompanhantes de sua escolha em um maternidade escola. J. res. fundam Care OnLine, 5 (3), 153-64.

- Andreucci, C. B., Cecatti, J. G. (2011). Desempenho de indicadores de processo do Programa de Humanização do pré-natal e nascimento no Brasil: uma revisão sistemática. Cad. Saúd. Pública, 27 (6), 1-8.

- Blummer, H. (1969). Symbolic interacionism perspective and method. Califórnia: Prentice-Hall.

- Brasil. (1984). Assistência Integral à Saúde da Mulher: bases de ação programática. Brasília (DF): Ministério da Saúde.

- Brasil. (2005). Lei 11.108 de 07 de abril de 2005. Altera a Lei $n^{\circ} 8080$, de 19 de setembro de 1990, para garantir as parturientes o direito à presença de acompanhante 
durante o trabalho de parto, parto e pós-parto imediato, no âmbito do Sistema Único de Saúde. Brasília (DF): Ministério da Saúde.

- Brasil. Ministério da Saúde (BR). (2012). Atenção ao pré-natal de baixo risco. Brasília (DF): Editora do Ministério da Saúde.

- Brasil. Portaria n. 1.459 de 24 de junho de 2011 (BR). (2011). Institui no âmbito do Sistema Único de Saúde SUS a Rede Cegonha. Brasília (DF). 24 de junho de 2011. Recuperado de http://bvsms.saude.gov.br/bvs/saudelegis/ gm/2011/prt1459 24062011 comp.html.

- Bruggemann, O. M., Ebsen, E. S., Oliveira, M. E., Gorayeb, M. K., \& Ebele, R. R. (2014). Motivos que levam os serviços de saúde a não permitirem acompanhante de parto: discursos de enfermeiros. Texto Contexto Enferm, Abr./Jun. 23 (2), 270-7. Recuperado de http://www.scielo.br/pdf/tce/v23n2/pt_0104-0707-tce-23-02-00270.pdf - Bruggemann, O. M., Oliveira, M. E., Martins, H. E. L., Alves, M. C., \& Gayeski, M. E. (2013) A inserção do acompanhante de parto nos serviços públicos de saúde de Santa Catarina, Brasil. Esc. Anna Nery,17 (3), 432-8.

- Carvalho, I. S., Júnior, P. B. C., Nunes, V. M. A., \& Macedo, J. P. O. (2011). Dificuldades relacionadas à presença do acompanhante durante o processo parturitivo da mulher: Percepção dos enfermeiros. Cuid. Fundam, (Ed. Supl.), 28-36. Recuperado de http://pesquisa.bvsalud. org/portal/resource/pt/bde-23334

- Carvalho, V. F., Kerber, N. P. C., Azambuja, E. P., Bueno, F. F., Silveira, R. S., \& Barros, A. M. (2014). Direitos das parturientes: conhecimento da adolescente e acompanhante. Saúde Soc, 23 (2), 572-81. Recuperado de http://www.scielo.br/pdf/sausoc/v23n2/0104-1290-sausoc-23-2-0572.pdf

- Costa, M. C. M. D. R. (2007). Vivendo o bem-estar no desconhecido: experiência da mulher com a presença do acompanhante no processo de parto [tese]. Natal (RN): Departamento de Enfermagem, Universidade Federal do Rio Grande do Norte.

- Diniz, C. S. G., d'Orsi, E., Domingues, R. M. S. M., Torres, J. Á., Dias, M. A. B., Schneck, C. A., Lansky, S., Teixeira, F. N. Z., Rance, S., \& Sandall, J. (2014). Implementation of the presence of companions during hospital admission for childbirth: data from the Birth in Brazil national survey. Cad. Saúd. Pública, 30 (Sup),140-53.

- Dodou, H. D., Rodrigues, D. P., Guerreiro, E. M., Guedes, M. V. C., Lago, P. N., \& Mesquita, N. S. (2014). A contribuição do acompanhante para humanização do parto e nascimento: Percepções de puérperas. Esc. Anna Nery, 8 (2), 262-9.

- Ebsen, E. S. (2015). Participação do acompanhante na atenção pré-natal: experiência dos profissionais de saúde da rede básica [tese]. Florianópolis: Universidade Federal de Santa Catarina.

- Flick, U. (2009). Introdução à pesquisa qualitativa. $3^{\mathrm{a}}$ ed. Porto Alegre: Artmed.

- Lacerda, A. C. B., Silva, R. A. R., \& Silva, R. M. B. (2014) Percepção das mulheres quanto ao acompanhante durante o trabalho de parto. Ver. Enferm UFPE, 8 (8), 2710-5.

- Moura, S. G., Melo, M. M. M., César, E. S. R., Silva, V. C. L., \& Filha, M. O. F. (2015). Assistência pré-natal realizada pelo enfermeiro (a): um olhar da mulher gestante. J. res.: fundam. Care. Online, 7 (3), 2930-8. Recuperado de http://pesquisa.bvs.br/brasil/resource/en/lil-762256

- Paz, L. S., \& Fensterseifer, L. M. (2011). Equipe de enfermagem e o acompanhante no parto em um hospital público de Porto Alegre. Rev. Interdisciplinar NOVAFAPI, 4 (1), 9-13. Santos, L. M., Carneiro, C. S., Carvalho, E. S. S., \& Paiva, M. S. (2012). Percepção da equipe de saúde sobre a presença do acompanhante no processo parturitivo. Ver. Rene, 13 (5),994-1003.

- Silva, F. F. A., Silva, R. A. R., Santos, F. A. P. S., \& Rego, A. P. (2014). Atendimento prestado a parturiente em um hospital universitário. J. res. fundam. Care On Line, 6 (1), 282-92. Recuperado de http://pesquisa.bvsalud.org/bra$\underline{\text { sil/resource/pt/bde-25393 }}$

- Villela, L. C. M., Galastro, E. P., Freitas, M. E. A., Santos, M. S. G., \& Notaro, K. A. M. (2011). Tempo de atuação do profissional enfermeiro - Minas Gerais. Enfermagem em foco, 4 (2), 248-50. Recuperado de http://revista.portalcofen.gov.br/index.php/enfermagem/article/view/194 